\title{
Artesunate treatment of severe pediatric malaria: A review of parasite clearance kinetics and clinical implications
}

\author{
Michael T Hawkes MD PhD ${ }^{1,2,3}$, Sarah Forgie MD MEd ${ }^{1}$, Jason Brophy MD MSc ${ }^{4}$, Maryanne Crockett MD MPH
}

S evere malaria causes an estimated 1.24 million deaths every year, mostly in children in sub-Saharan Africa (1). Canadian pediatric infectious diseases practitioners may encounter life-threatening malaria among children emigrating from or returning from travel to the tropics. There were 195 reported cases of severe malaria in Canada between 2001 and 2012 (2), and the recent death of a malaria-infected adult in Alberta provided a reminder of the potential severity of the disease. Two large, multicentre, randomized controlled trials conclusively demonstrated a mortality benefit for the use of artesunate over quinine, the centuries-old standard, for children and adults with severe malaria $(3,4)$. As a result, intravenous artesunate is now the treatment of choice for severe malaria, as reflected in guidelines from the WHO and the Canadian Committee to Advise on Tropical Medicine and Travel $(5,6)$.

Severe malaria in children most often manifests as either a single, or a combination of three clinical syndromes: severe malarial anemia, cerebral malaria and/or respiratory distress. In addition, patients with a high parasite density are at elevated risk for progression to severe disease and death. In travellers from low-transmission settings, such as Canada, the parasitemia threshold suggested for close monitoring, hospitalization and parenteral therapy is $>2 \%(6)$. It should be emphasized that circulating parasites represent only a fraction of the sequestered parasite biomass in severe malaria, such that this threshold is imprecise.

Artesunate is a water-soluble, semi-synthetic derivative of artemisinin, the active antimalarial component of the herb Artemisia annua (qinghaosu). Its use in clinical practice is expanding in malariaendemic areas of Africa and Asia, replacing quinine as the mainstay of severe malaria treatment (7). It is available across Canada, $24 \mathrm{~h}$ per day, through the Canadian Malaria Network and Health Canada's Special Access Program (8). If, despite national efforts to ensure its accessibility, artesunate cannot be obtained in a timely manner for a patient with severe malaria, alternative agents (eg, atovaquone-proguanil or quinine) should be initiated pending arrival of artesunate.

Although the weight of evidence and international consensus favour artesunate treatment, some countries continue to list quinidine or quinine for severe malaria as they await regulatory approval of artesunate $(9,10)$. Clinicians consulting widely available online $(9,11)$ or print $(10,12)$ treatment guidelines for severe malaria may be puzzled by the United States (US) Centers for Disease Control and Prevention's listing of quinidine as first-line therapy in the US, or quinine in the United Kingdom (Table 1). WHO-prequalified artesunate (Guilin Pharmaceutical, China) was used in major clinical trials with excellent efficacy (3); however, it has not yet obtained Health Canada, US Food and Drug Administration or European Union regulatory approval, creating a gap between the preferred evidence-based regimen and the regimen approved by regulatory authorities. High-quality artesunate from the Walter Reed Army Institute of Research (Maryland, USA) is, nonetheless, widely used in Canada and the US, made available to Canadians through the Canadian Malaria Network (2) and to US hospitals through a Food and Drug Administration-approved investigational new drug protocol (9).

In addition to reducing mortality in patients with severe malaria, artesunate treatment also results in remarkably rapid parasite clearance. The kinetics of parasite elimination from the peripheral circulation under artesunate treatment are summarized in Table 2. Parasite clearance kinetics link the three themes discussed in the present article: postartemisinin-delayed hemolysis (PADH), a newly recognized adverse event and consequence of rapid parasite clearance; pharmacokinetics and dosing in young children who exhibit slower parasite clearance; and artesunate resistance, heralded by slow parasite clearance.

\section{POSTARTEMISININ-DELAYED HEMOLYSIS}

The safety profile of parenteral artesunate in the largest randomized trials to date was excellent, with essentially no serious drug-related adverse effects reported. Compared with quinine, the incidence of post-treatment hypoglycemia and neurological progression (new seizures, development of coma) was lower $(3,4)$. Artesunate is, therefore, preferred not only for its superior efficacy over quinine, but also its lack of acute toxicity.

As artesunate use expanded to include nonimmune returning travellers with severe malaria, reports emerged of hemolytic anemia occurring weeks after treatment (13). This late sequela of artesunate treatment was not reported in earlier studies because they only had a three-day median for follow-up of hemoglobin levels (14).

Anemia with malaria is multifactorial, and can be due to parasite and host factors, in addition to antimalarials. For example, severe anemia (hemoglobin $<50 \mathrm{~g} / \mathrm{L}$ ) is the most common pediatric presentation of severe malaria (15), and severe acute intravascular hemolysis ('blackwater fever') occurs in the acute phase in both quinine- and artesunate-treated patients (3). During recovery, protracted anemia was observed in up to $7 \%$ of patients even before the introduction of artesunate (16), which may be caused by bone marrow suppression and/ or hemolysis due to autoimmune and nonimmune processes (17-19). Drug-induced hemolytic anemia related to glucose-6-phosphate dehydrogenase (G6PD) deficiency may also contribute to anemia.

PADH has recently been recognized as a clinically and mechanistically distinct entity that only occurs in patients with severe malaria treated with artesunate. PADH occurs well after parasite clearance and resolution of clinical symptoms, and is not consistently associated with markers of autoimmune hemolysis (eg, positive direct antiglobulin test)

${ }^{1}$ Department of Pediatrics; ${ }^{2}$ School of Public Health; ${ }^{3}$ Department of Medical Microbiology and Immunology, University of Alberta, Edmonton, Alberta; ${ }^{4}$ Department of Pediatrics, Children's Hospital of Eastern Ontario, Ottawa, Ontario; ${ }^{5}$ Departments of Pediatrics and Child Health, Medical Microbiology and Community Health Sciences, University of Manitoba, Winnipeg, Manitoba

Correspondence: Dr Michael T Hawkes, Edmonton Clinic Health Academy, 3-588D 1140587 Avenue, Edmonton, Alberta, T6G 1C9.

E-mail mthawkes@ualberta.ca 
TABLE 1

Guideline confusion: summary of recommendations for treatment of severe malaria from several national guidelines

\begin{tabular}{|c|c|c|}
\hline Country & Source & Statement \\
\hline Global & World Health Organization (6) & $\begin{array}{l}\text { Treat adults and children with severe malaria with parenteral artesunate. } \\
\text { (Strong recommendation, high quality evidence) }\end{array}$ \\
\hline Canada & $\begin{array}{l}\text { Canadian Committee to Advise on Tropical Medicine } \\
\text { and Tropical Medicine and Travel (CATMAT) (2) }\end{array}$ & $\begin{array}{l}\text { "Parenteral artesunate is recommended as first-line treatment for severe Plasmodium falci- } \\
\text { parum malaria, with parenteral quinine as an alternative." (Good evidence from at least } \\
\text { one properly randomized controlled trial) }\end{array}$ \\
\hline United States & $\begin{array}{l}\text { United States Centers for Disease Control and } \\
\text { Prevention (9) }\end{array}$ & $\begin{array}{l}\text { "Since 1991, quinidine gluconate has been the only parenterally administered antimalarial } \\
\text { drug available in the United States." } \\
\text { "Artesunate is recommended by the World Health Organization in preference to } \\
\text { quinidine for the treatment of severe malaria and has been used worldwide for many years." }\end{array}$ \\
\hline $\begin{array}{l}\text { United Kingdom } \\
\text { (UK) }\end{array}$ & $\begin{array}{l}\text { Public Health England } \\
\text { British Infection Association (11) }\end{array}$ & $\begin{array}{l}\text { "In the UK, the treatment of choice for severe or complicated malaria is currently an infu- } \\
\text { sion of intravenous quinine." } \\
\text { "Intravenous artesunate reduces high parasite loads more rapidly than quinine and is more } \\
\text { effective in treating severe malaria in selected situations. It can also be used in patients } \\
\text { with contraindications to quinine. Intravenous artesunate is unlicensed in the EU." }\end{array}$ \\
\hline
\end{tabular}

EU European Union

or erythrocyte susceptibility to oxidative stress (eg, G6PD deficiency) $(20,21)$. Although artesunate may cause reversible bone marrow suppression, this mechanism likely contributes minimally to postartesunate anemia (22). Instead, PADH involves a distinct mechanism of hemolytic anemia, discussed below (22).

Clinically, several patterns of anemia following artesunate treatment of severe malaria are observed, including a 'rising' hemoglobin profile following early nadir, 'persistent' anemia and late-onset extravascular hemolysis beyond day 8 (PADH pattern) (22). To distinguish PADH from the myriad causes of anemia in severe malaria, a specific case definition of PADH has been proposed, and includes: a nonrecurring hemolytic episode occurring $>7$ days after initiation of treatment, with artesunate associated with a $>10 \%$ decrease in hemoglobin level; haptoglobin $<0.1 \mathrm{~g} / \mathrm{L}$; and either an increase in lactate dehydrogenase to $>390 \mathrm{IU} / \mathrm{L}$ or a $>10 \%$ rise $(23)$.

The incidence of PADH is difficult to quantify with currently available data because of the variability in case definitions used in the literature since its relatively recent description. A systematic review of the literature up to 2014, revealed 37 cases of hemolysis and estimated an incidence rate of $13 \%$ among patients with severe malaria treated with artemisinin derivatives. However, this report did not use the optimized case definition of PADH; application of the more specific case definition would result in a lower incidence rate $(22,24)$. The majority of these cases involved nonimmune adult returning travellers receiving intravenous artesunate. Reports of PADH from North America are surprisingly uncommon relative to Europe (24). The incidence among children with severe malaria in an endemic area has been estimated to be $7 \%$; however, the reduction in hemoglobin in this report was $<10 \mathrm{~g} / \mathrm{L}$ in all but one patient (25). Again, applying the more specific definition of $\mathrm{PADH}$ would result in a lower incidence rate estimate.

The severity of anemia in reports of PADH is variable. In a systematic review of mostly adult cases, the median reduction in hemoglobin level was $60 \mathrm{~g} / \mathrm{L}$, and $73 \%$ of patients required blood transfusions (24). One study involving children revealed a median reduction in hemoglobin of $8 \mathrm{~g} / \mathrm{L}$, although one patient was noted to have a decrease of $42 \mathrm{~g} / \mathrm{L}$ (25). No fatal outcome has been reported in the literature to date.

The mechanism of PADH has been elucidated in recent studies. Malaria parasites killed by artesunate are removed from erythrocytes by the spleen, leaving behind once-infected erythrocytes (o-iE). These o-iEs have a 'pitted' appearance, remaining in circulation with a considerably decreased life span of seven to 21 days $(26,27)$. This reduced life span correlates with the timing of the onset of PADH, and may account for the higher risk for PADH among patients with higher initial parasite densities in whom higher numbers of o-iEs were observed. Therefore, PADH is a predictable consequence related to the life-saving effect of artemisinins: patients with high parasite burden rapidly cleared with artesunate, who may otherwise have succumbed to the acute infection, are left with high numbers of residual short-lived pitted erythrocytes.

\section{PEDIATRIC PHARMACOKINETICS AND DOSING}

Inspection of artesunate-clearance half-life across clinical studies illustrated slower parasite clearance in children relative to adults (Table 2). Quantitative measures of parasite clearance are affected not only by parasite genetics and drug susceptibility $(28,29)$, but also by host determinants including patient age, organ function, drug metabolism and immunity. Therefore, lack of acquired partial immunity (premunition) in pediatric cohorts and/or age-dependent pharmacokinetic differences (30) may explain, at least in part, the slower parasite clearance in children relative to adults $(31,32)$. Differences in pharmacokinetics, leading to lower exposure to the active metabolite dihydroartemisinin, has led to revised dosing recommendations in the $2015 \mathrm{WHO}$ Guidelines for the Treatment of Malaria (6): children weighing $<20 \mathrm{~kg}$ should receive $3.0 \mathrm{mg} / \mathrm{kg} /$ dose of artesunate, rather than the dose for larger children or adults of $2.4 \mathrm{mg} / \mathrm{kg} / \mathrm{dose}(30,33)$.

\section{EMERGING ARTEMISININ RESISTANCE}

Artemisinin-resistant Plasmodium falciparum has recently emerged and spread in Southeast Asia, threatening the efficacy of first-line treatment regimens for severe and uncomplicated malaria worldwide (3437). Resistance to artemisinins manifests as a slower parasite clearance rate in vivo $(28,34,38)$. The parasite-clearance half-life, derived from the log-linear decline in parasite density during treatment, is now widely accepted as the best pharmacodynamic index of $P$ falciparum sensitivity to artemisinins (39-43). Parasite clearance time and clearance half-life are compared across studies in Table 2. Nonsynonymous single-nucleotide polymorphisms in the propeller domain of a kelch (K13) gene are generally accepted as the major genetic determinant of artemisinin resistance in $P$ falciparum $(35,40,43,44)$. The mechanism involves increased expression of unfolded protein response pathways (eg, chaperone complexes), as well as decreased expression of proteins involved in DNA replication among mutant parasites. These K13 polymorphisms have emerged independently in multiple geographic locations in Southeast Asia, suggesting that selection pressure may drive the selection of resistant isolates as artemisinin treatment is distributed worldwide (44). To date, only limited numbers of infections with K13 mutants have been detected in Africa (45-47). One report has linked K13 mutations to delayed parasite clearance in African children treated with artesunate for severe malaria (48).

Artemisinin resistance has alarming implications for malaria control globally. Artemisisnin combination therapy is the first-line agent for uncomplicated falciparum malaria, and parenteral artesunate is the 


\begin{tabular}{|c|c|c|c|c|c|c|c|}
\hline Country & Study population & $\mathbf{n}$ & Disease severity & Treatment & $\begin{array}{c}\text { Median } \\
\text { parasite } \\
\text { clearance } \\
\text { time, h }\end{array}$ & $\begin{array}{c}\text { Median } \\
\text { clearance } \\
\text { half-life, h }\end{array}$ & Reference \\
\hline Uganda & Children $1-10$ years of age & 71 & Severe & IV artesunate* & 44 & 4.6 & Hawkes et al (39) \\
\hline Malawi and Gabon & Children $0.5-10$ years of age & 171 & Hospitalized & IV artesunate & 36 & NR & Kremsner et al (49) \\
\hline Mali & Children $0.5-15$ years of age & 215 & Uncomplicated & $\begin{array}{l}\text { PO artesunate } \\
(4 \mathrm{mg} / \mathrm{kg} / \text { day })^{\dagger}\end{array}$ & 24 & 1.9 & $\begin{array}{l}\text { Lopera-Mesa et al } \\
\text { (31) }\end{array}$ \\
\hline Sudan & Adults $(60 \%)$ and children $(40 \%)^{*}$ & 47 & Severe & IV artesunate* & 16.5 & NR & Abdallah et al (50) \\
\hline Kenya & NR & 171 & NR & NR & NR & 2.5 & Flegg et al (51) \\
\hline $\begin{array}{l}20 \text { sub-Saharan } \\
\text { African countries }\end{array}$ & $\begin{array}{l}\text { Predominantly children }<6 \text { years of age } \\
(77 \%)\end{array}$ & 15,017 & Uncomplicated & $\begin{array}{l}\text { PO artesunate- } \\
\text { amodiaquine }\end{array}$ & 31 & $2.5^{\ddagger}$ & Zwang et al (52) \\
\hline Bangladesh & Adults & 27 & Severe & IV artesunate* & 48 & 2.5 & Maude et al (53) \\
\hline Laos & Youth and adults $\geq 10$ years of age & 44 & Uncomplicated & $\begin{array}{l}\text { PO artesunate } \\
(2-4 \mathrm{mg} / \mathrm{kg} / \text { day })\end{array}$ & 23 & 1.93 & Mayxay et al (54) \\
\hline Thailand & Adults $\geq 15$ years of age & 591 & Severe & IV artesunate* & 62.5 & NR & Newton et al (55) \\
\hline Thailand (Wang Pha) & Adults $>16$ years of age* & 20 & Uncomplicated & $\begin{array}{l}\text { PO artesunate } \\
(2 \mathrm{mg} / \mathrm{kg} / \mathrm{day})^{*}\end{array}$ & 54 & 2.2 & $\begin{array}{l}\text { Dondorp et al (34) } \\
\text { Amaratunga et al (28) }\end{array}$ \\
\hline Thailand (Wang Pha) & Adult patients $\geq 18$ yearsof age & 80 & Uncomplicated & $\begin{array}{l}\text { PO artesunate } \\
(6-8 \mathrm{mg} / \mathrm{kg} / \text { day })^{\dagger}\end{array}$ & 48 & 3.4 & Das et al (38) \\
\hline Cambodia (Pursat) & Youth and adults $>10$ years of age & 168 & Uncomplicated & $\begin{array}{l}\text { PO artesunate } \\
(4 \mathrm{mg} / \mathrm{kg} / \text { day })\end{array}$ & 78 & 5.9 & Amaratunga et al (28) \\
\hline Cambodia (Pailin) & $\begin{array}{l}\text { Children } 5-16 \text { years of age }(28 \%) \text { and } \\
\text { adults* }\end{array}$ & 20 & Uncomplicated & $\begin{array}{l}\text { PO artesunate } \\
(2 \mathrm{mg} / \mathrm{kg} / \mathrm{day})^{*}\end{array}$ & 84 & 5.4 & $\begin{array}{l}\text { Dondorp et al (34) } \\
\text { Amaratunga et al (28) }\end{array}$ \\
\hline Cambodia (Pailin) & $\begin{array}{l}\text { Children } 6-18 \text { years of age }(28 \%) \text { and } \\
\text { adults }\end{array}$ & 79 & Uncomplicated & $\begin{array}{l}\text { PO artesunate } \\
(6-8 \mathrm{mg} / \mathrm{kg} / \text { day })^{\dagger}\end{array}$ & 78 & 6.0 & Das et al (38) \\
\hline
\end{tabular}

${ }^{*}$ From the placebo arm of a randomized controlled trial; Data derived from patients in the study treated with intravenous (IV) artesunate as sole antimalarial agent; ${ }^{\dagger}$ Oral (PO) artesunate was used as monotherapy for the first $72 \mathrm{~h}$ of treatment, the time during which kinetic parameters were calculated; ${ }^{\ddagger}$ Not directly reported, but calculated from published results. NR Not reported

treatment of choice for severe malaria, highlighting our current reliance on this drug class. Alternative effective and safe agents are limited, and artemisinins are believed to be have contributed to the decline in malaria deaths globally over the past decade.

Nonetheless, clinicians managing patients with severe malaria acquired in Southeast Asia should continue to use artesunate for the time being. Safety advantages of artesunate over quinine favour its continued use in clinical practice. It should be emphasized that the phenotype of resistant $P$ falciparum clones described to date is delayed parasite clearance, rather than nonresponse or increased mortality. Slow-clearing parasites may require longer courses of therapy or alternative antimalarial regimens. Serial quantitative determination of parasite density (eg, daily peripheral blood smear), which is the standard of care in $P$ falciparum infection, will reflect parasite response to treatment. Note that the presence of gametocytes (sexual-stage parasites) alone in a peripheral smear does not imply treatment failure because this stage is less sensitive to artesunate and is not associated with symptoms or disease.

\section{REFERENCES}

1. Murray CJ, Rosenfeld LC, Lim SS, et al. Global malaria mortality between 1980 and 2010: A systematic analysis. Lancet 2012;379:413-31.

2. Committee to Advise on Tropical Medicine and Tropical Medicine and Travel (CATMAT). Canadian Recommendations for the Prevention and Treatment of Malaria. <www.publications.gc.ca/ collections/collection_2014/aspc-phac/HP40-102-2014-eng.pdf> (Accessed August 20, 2015).

3. Dondorp AM, Fanello CI, Hendriksen IC, et al. Artesunate versus quinine in the treatment of severe falciparum malaria in African children (AQUAMAT): An open-label, randomised trial. Lancet 2010;376:1647-57.

4. Dondorp A, Nosten F, Stepniewska K, Day N, White N, South East Asian Quinine Artesunate Malaria Trial g. Artesunate versus quinine for treatment of severe falciparum malaria: A randomised trial. Lancet 2005;366:717-25.

5. Boggild A, Brophy J, Charlebois P, et al. Summary of recommendations for the diagnosis and treatment of malaria by the Committee to Advise

\section{CONCLUSION}

We have summarized three relevant or emerging practice points for pediatric infectious diseases clinicians managing children with severe malaria using artesunate. First, as an unintended consequence of rapid parasite killing, clinicians should monitor for delayed hemolysis, with hemoglobin measurement weekly, up to four weeks after treatment. Second, pediatricians should be aware of the need for a higher weightbased dose in young children due to pharmacokinetic differences in artesunate metabolism, resulting in slower parasite clearance in young children. Third, artemisinin resistance associated with slow parasite clearance is emerging in Southeast Asia; nonetheless, clinicians should continue to use artesunate while monitoring for parasite clearance with serial blood smears.

ACKNOWLEDGEMENTS: The authors thank Dr Stan Houston for his critical review of the manuscript and helpful suggestions.

on Tropical Medicine and Travel (CATMAT). Canada Communicable Disease Report CCDR 2014;40-7.

6. WHO. Guidelines for the Treatment of Malaria. Third Edition. <www.who.int/malaria/publications/atoz/9789241549127/en/> (Accessed August 20, 2015).

7. Noubiap JJ. Shifting from quinine to artesunate as first-line treatment of severe malaria in children and adults: Saving more lives. J Infect Public Health 2014;7:407-12.

8. Public Health Agency of Canada. Medical Access to Artesunate or Quinine for Malaria Treatment Streamlined in Canada through the Canadian Malaria Network (CMN). 2014. <www.phac-aspc.gc.ca/ tmp-pmv/quinine/index-eng.php.> (Accessed August 20, 2015).

9. US Centers for Disease Control and Prevention (CDC). Treatment of Malaria: Guidelines For Clinicians (United States). Part 3: Alternatives for Pregnant Women and Treatment of Severe Malaria. <www.cdc.gov/malaria/diagnosis_treatment/clinicians3.html> (Accessed August 20, 2015). 
10. Gilbert DN. Sanford Guide to Antimicrobial Therapy 2015 (45th ed) Sperryville, VA 2015.

11. British Infection Association. Malaria Treatment Guidelines. <www.britishinfection.org/guidelines-resources/published-guidelines/> (Accessed August 20, 2015).

12. Lalloo DG, Shingadia D, Pasvol G, et al. UK malaria treatment guidelines. J Infect 2007;54:111-21.

13. Rolling T, Schmiedel S, Wichmann D, Wittkopf D, Burchard GD, Cramer JP. Post-treatment haemolysis in severe imported malaria after intravenous artesunate: Case report of three patients with hyperparasitaemia. Malar J 2012;11:169.

14. Dondorp AM, Fanello CI, Hendriksen IC, et al. Artesunate versus quinine in the treatment of severe falciparum malaria in African children (AQUAMAT): An open-label, randomised trial. Lancet 2010;376:1647-57.

15. Marsh K, Forster D, Waruiru C, et al. Indicators of life-threatening malaria in African children. N Engl J Med 1995;332:1399-404.

16. Camacho LH, Gordeuk VR, Wilairatana P, et al. The course of anaemia after the treatment of acute, falciparum malaria. Ann Trop Med Parasitol 1998;92:525-37.

17. Adner MM, Altstatt LB, Conrad ME. Coombs'-positive hemolytic disease in malaria. Ann Intern Med 1968;68:33-8.

18. Omodeo-Sale F, Motti A, Dondorp A, White NJ, Taramelli D. Destabilisation and subsequent lysis of human erythrocytes induced by Plasmodium falciparum haem products. Eur J Haematol 2005;74:324-32.

19. Woodruff AW, Ansdell VE, Pettitt LE. Cause of anaemia in malaria. Lancet 1979;1:1055-7.

20. Zoller T, Junghanss T, Kapaun A, et al. Intravenous artesunate for severe malaria in travelers, Europe. Emerg Infect Dis 2011;17:771-7.

21. Kreeftmeijer-Vegter AR, van Genderen PJ, Visser LG, et al. Treatment outcome of intravenous artesunate in patients with severe malaria in the Netherlands and Belgium. Malar J 2012;11:102.

22. Jaureguiberry S, Ndour PA, Roussel C, et al. Postartesunate delayed hemolysis is a predictable event related to the lifesaving effect of artemisinins. Blood 2014;124:167-75.

23. Arguin PM. Case definition: Postartemisinin delayed hemolysis. Blood 2014;124:157-8.

24. Rehman K, Lotsch F, Kremsner PG, Ramharter M. Haemolysis associated with the treatment of malaria with artemisinin derivatives: A systematic review of current evidence. Int J Infect Dis 2014;29:268-73.

25. Rolling T, Agbenyega T, Issifou S, et al. Delayed hemolysis after treatment with parenteral artesunate in African children with severe malaria-a double-center prospective study. J Infect Dis 2014;209:1921-8.

26. Newton PN, Chotivanich K, Chierakul W, et al. A comparison of the in vivo kinetics of Plasmodium falciparum ring-infected erythrocyte surface antigen-positive and -negative erythrocytes. Blood 2001;98:450-7.

27. Chotivanich K, Udomsangpetch R, Dondorp A, et al. The mechanisms of parasite clearance after antimalarial treatment of Plasmodium falciparum malaria. J Infect Dis 2000;182:629-33.

28. Amaratunga C, Sreng S, Suon S, et al. Artemisinin-resistant Plasmodium falciparum in Pursat province, western Cambodia: A parasite clearance rate study. Lancet Infect Dis 2012;12:851-8.

29. Takala-Harrison S, Clark TG, Jacob CG, et al. Genetic loci associated with delayed clearance of Plasmodium falciparum following artemisinin treatment in Southeast Asia. Proc Natl Acad Sci USA 2012;110:240-5.

30. Zaloumis SG, Tarning J, Krishna S, et al. Population pharmacokinetics of intravenous artesunate: A pooled analysis of individual data from patients with severe malaria. CPT Pharmacometrics Syst Pharmacol 2014;3:e145.

31. Lopera-Mesa TM, Doumbia S, Chiang S, et al. Plasmodium falciparum clearance rates in response to artesunate in Malian children with malaria: Effect of acquired immunity. J Infect Dis 2013;207:1655-63.

32. Mayxay M, Khanthavong M, Chanthongthip O, et al. Efficacy of artemether-lumefantrine, the nationally-recommended artemisinin combination for the treatment of uncomplicated falciparum malaria, in southern Laos. Malar J 2012;11:184.
33. Hendriksen IC, Mtove G, Kent A, et al. Population pharmacokinetics of intramuscular artesunate in African children with severe malaria: Implications for a practical dosing regimen. Clin Pharmacol Ther 2013;93:443-50.

34. Dondorp AM, Nosten F, Yi P, et al. Artemisinin resistance in Plasmodium falciparum malaria. N Engl J Med 2009;361:455-67.

35. Ariey F, Witkowski B, Amaratunga C, et al. A molecular marker of artemisinin-resistant Plasmodium falciparum malaria. Nature 2014;505:50-5.

36. Witkowski B, Amaratunga C, Khim N, et al. Novel phenotypic assays for the detection of artemisinin-resistant Plasmodium falciparum malaria in Cambodia: In-vitro and ex-vivo drug-response studies. Lancet Infect Dis 2013;13:1043-9.

37. Venkatesan M, Gadalla NB, Stepniewska K, et al. Polymorphisms in Plasmodium falciparum chloroquine resistance transporter and multidrug resistance 1 genes: Parasite risk factors that affect treatment outcomes for P. falciparum malaria after artemetherlumefantrine and artesunate-amodiaquine. Am J Trop Med Hyg 2014;91:833-43.

38. Das D, Tripura R, Phyo AP, et al. Effect of high-dose or split-dose artesunate on parasite clearance in artemisinin-resistant falciparum malaria. Clin Infect Dis 2012;56:e48-e58.

39. Hawkes M, Conroy AL, Kain KC. Spread of artemisinin resistance in malaria. N Engl J Med 2014;371:1944-5.

40. Ashley EA, Dhorda M, Fairhurst RM, et al. Spread of artemisinin resistance in Plasmodium falciparum malaria. N Engl J Med 2014;371:411-23.

41. Saralamba S, Pan-Ngum W, Maude RJ, et al. Intrahost modeling of artemisinin resistance in Plasmodium falciparum. Proc Natl Acad Sci USA 2011;108:397-402.

42. White NJ. The parasite clearance curve. Malar J 2011;10:278.

43. Mok S, Ashley EA, Ferreira PE, et al. Population transcriptomics of human malaria parasites reveals the mechanism of artemisinin resistance. Science 2015;347:431-5.

44. Takala-Harrison S, Jacob CG, Arze C, et al. Independent emergence of artemisinin resistance mutations among Plasmodium falciparum in Southeast Asia. J Infect Dis 2015;211:670-9.

45. Torrentino-Madamet M, Fall B, Benoit N, et al. Limited polymorphisms in $\mathrm{k} 13$ gene in Plasmodium falciparum isolates from Dakar, Senegal in 2012-2013. Malar J 2014;13:472.

46. Conrad MD, Bigira V, Kapisi J, et al. Polymorphisms in K13 and falcipain-2 associated with artemisinin resistance are not prevalent in Plasmodium falciparum isolated from Ugandan children. PloS one 2014;9:e105690.

47. Taylor SM, Parobek CM, DeConti DK, et al. Absence of putative artemisinin resistance mutations among Plasmodium falciparum in sub-Saharan Africa: A molecular epidemiologic study. J Infect Dis 2015;211:680-8.

48. Hawkes M, Conroy AL, Opoka RO, et al. Slow clearance of Plasmodium falciparum in severe pediatric malaria, Uganda, 2011-2013. Emerg Infect Dis 2015;21:1237-9.

49. Kremsner PG, Taylor T, Issifou S, et al. A simplified intravenous artesunate regimen for severe malaria. J Infect Dis 2011;205:312-9.

50. Abdallah TM, Elmardi KA, Elhassan AH, et al. Comparison of artesunate and quinine in the treatment of severe Plasmodium falciparum malaria at Kassala hospital, Sudan. J Infect Dev Ctries 2014;8:611-5.

51. Flegg JA, Guerin PJ, White NJ, Stepniewska K. Standardizing the measurement of parasite clearance in falciparum malaria: The parasite clearance estimator. Malar J 2011;10:339.

52. Zwang J, Dorsey G, Martensson A, et al. Plasmodium falciparum clearance in clinical studies of artesunate-amodiaquine and comparator treatments in sub-Saharan Africa, 1999-2009. Malar J 2014;13:114.

53. Maude RJ, Silamut K, Plewes K, et al. Randomized controlled trial of levamisole hydrochloride as adjunctive therapy in severe falciparum malaria with high parasitemia. J Infect Dis 2014;209:120-9.

54. Mayxay M, Khanthavong M, Chanthongthip O, et al. No evidence for spread of Plasmodium falciparum artemisinin resistance to Savannakhet Province, Southern Laos. Am J Trop Med Hyg 2012;86:403-8.

55. Newton PN, Angus BJ, Chierakul W, et al. Randomized comparison of artesunate and quinine in the treatment of severe falciparum malaria. Clin Infect Dis 2003;37:7-16. 


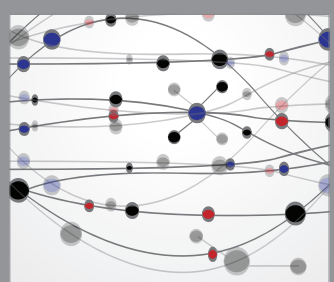

The Scientific World Journal
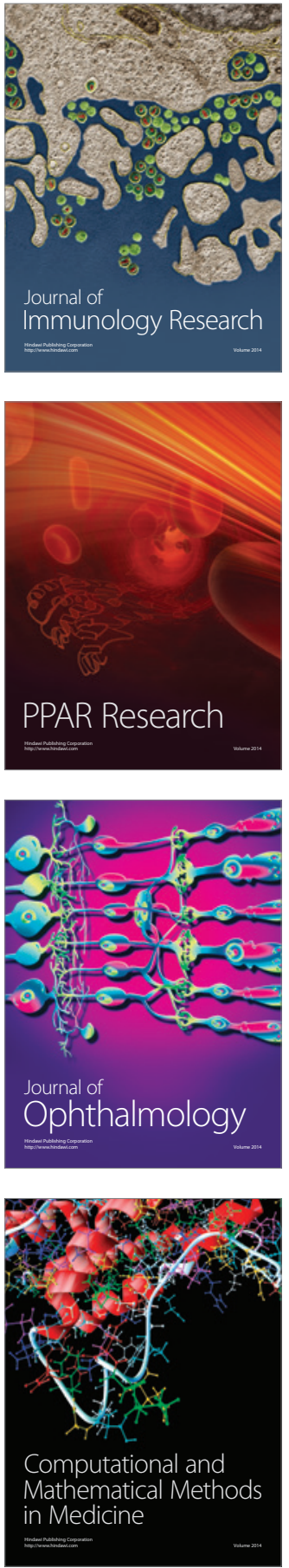

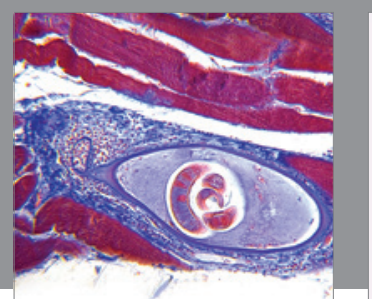

Gastroenterology Research and Practice

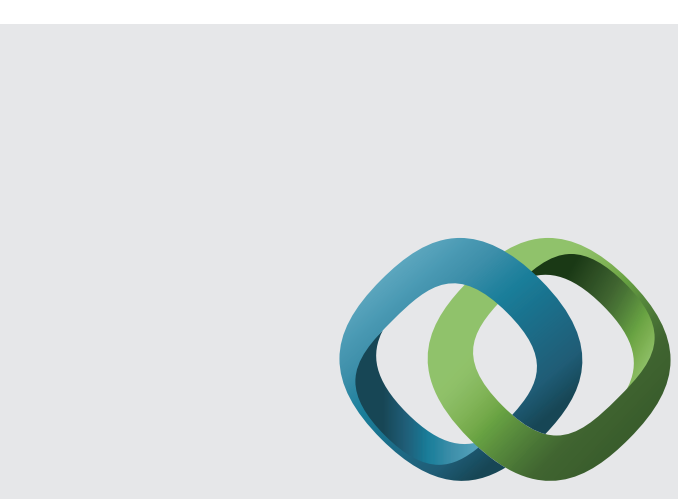

\section{Hindawi}

Submit your manuscripts at

http://www.hindawi.com
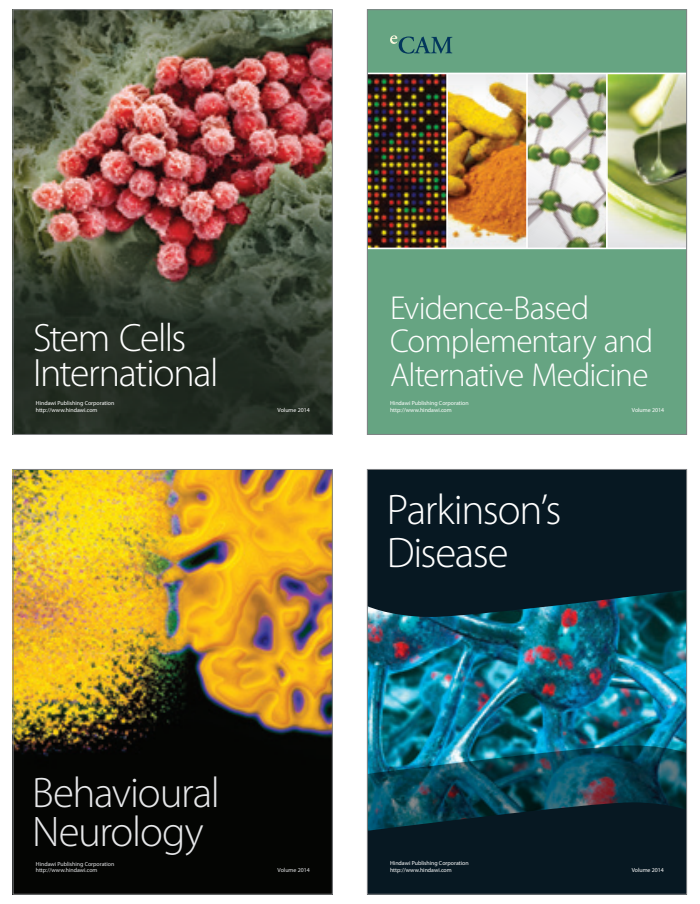
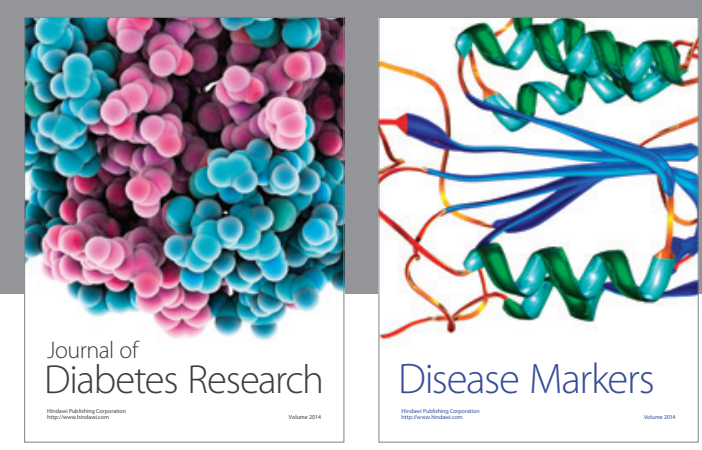

Disease Markers
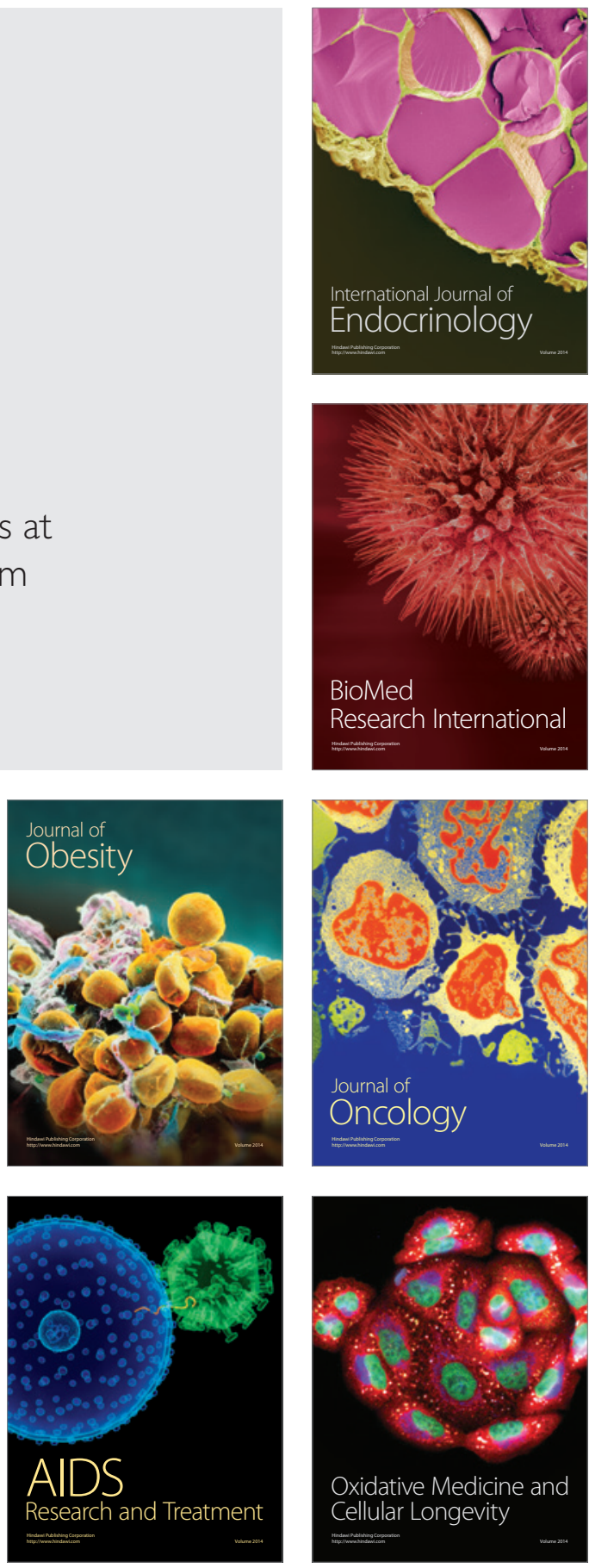